\title{
Effect of carbohydrate rich versus fat rich loads on gas exchange and walking performance in patients with chronic obstructive lung disease
}

\author{
J Efthimiou, P J Mounsey, D N Benson, R Madgwick, S J Coles, M K Benson
}

\begin{abstract}
Background High calorie intakes, especially as carbohydrate, increase carbon dioxide production $\left(\mathrm{V}_{\mathrm{CO}_{2}}\right)$ and may precipitate respiratory failure in patients with severe pulmonary disease. Energy obtained from fat results in less carbon dioxide and thus may permit a reduced level of alveolar ventilation for any given arterial blood carbon dioxide tension $\left(\mathbf{P a C O}_{2}\right)$.
\end{abstract}

Methods Ten patients with stable severe chronic obstructive lung disease underwent a six minute walk before and 45 minutes after taking $920 \mathrm{kcal}$ of a fat rich drink, an isocalorific amount of a carbohydrate rich drink, and an equal volume of a non-calorific control liquid on three separate days, in a double blind randomised crossover study. Borg scores of the perceived effort to breathe were measured at the beginning and end of each six minute walk. Minute ventilation $\left(\dot{\mathbf{V}} \mathrm{E}_{2}\right), \dot{\mathbf{V}} \mathrm{Co}_{2}$, oxygen consumption $\left(\dot{\mathbf{V}} \mathrm{o}_{2}\right)$, respiratory quotient (RQ), arterial blood gas tensions, and lung function were measured before and 30 minutes after each test drink.

Results Baseline measurements were similar on all three test days and the non-calorific control drink resulted in no changes in any of the measured variables. The carbohydrate rich drink resulted in significantly greater increases in $\dot{V} E, \dot{V}_{C O_{2}}, \dot{V} o_{2}, R Q, \mathbf{P a C O}_{2}$, and Borg score and a greater fall in the distance walked in six minutes than the fat rich drink (mean fall after carbohydrate rich drink $17 \mathrm{~m} v 3 \mathrm{~m}$ after fat rich drink and the non-calorific control). The increase in $\dot{V} \mathrm{CO}_{2}$ correlated significantly with the decrease in six minute walking distance and the increase in Borg score after the carbohydrate rich drink. The only significant change after the fat rich drink when compared with the non-calorific control was an increase in $\mathbf{V} \mathrm{CO}_{2}$.

Conclusions Comparatively

small

Osler Chest Unit, Churchill Hospital, Oxford OX3 7LJ

J Efthimiou

P J Mounsey

D N Benson

R Madgwick

$S \mathrm{~J}$ Coles

M K Benson

Address for correspondence: Dr J Efthimiou

Accepted 18 January 1992
Introduction

Patients with severe chronic obstructive lung disease possess little ventilatory reserve and disease possess little ventilatory reserve and are at risk of developing acute respiratory failure, with hypercapnia as a complication. The hypercapnia in these patients has generally been attributed to mechanical factors limiting ventilation and to reduced central respiratory drive. ${ }^{2}$ The potential adverse effects of carbohydrate loads in patients with chronic obstructive lung disease, particularly with regard to carbon dioxide production $\left(\dot{\mathrm{V}} \mathrm{CO}_{2}\right)$, has received considerable attention recently. ${ }^{3-5}$

The absorption and metabolism of carbohydrate loads in normal subjects causes an increase in $\dot{\mathrm{VCO}}_{2}$ and respiratory quotient (RQ). ${ }^{6}$ The increase in $\dot{\mathrm{COO}}_{2}$ results from a shift in net whole body fuel utilisation from predominantly fat (metabolised with an $R Q$ of 0.7 ) to predominantly carbohydrate (metabolised with an RQ of 1.0 ), as well as from the thermogenic effect of food itself. ${ }^{78}$ In addition, ingestion of carbohydrate in excess of energy requirements may result in lipogenesis, leading to a further increase in $\mathrm{VCO}_{2}{ }^{79}$

The increased load of carbon dioxide must be eliminated predominantly by the lungs, and people with normal lungs do this easily. ${ }^{6}$ Patients with chronic obstructive lung disease, who are prone to hypercapnia, are less able to excrete this load, and the optimal management of these patients may involve a shift from a diet that is predominantly carbohydrate to one with a greater proportion of fat. The net effect of such a change should be a lower $\mathrm{VCO}_{2}$ and a reduced tendency to hypercapnia, possibly with symptomatic benefit in terms of improved exercise tolerance.

This study was designed to compare the effect of carbohydrate and fat rich loads on $\mathrm{VCO}_{2}$, oxygen consumption $\left(\dot{\mathrm{V}}_{2}\right), \mathrm{RQ}$, and exercise tolerance in patients with stable chronic obstructive lung disease, in a controlled double blind randomised crossover manner.

\section{Methods}

PATIENTS

Ten patients (seven men, three women) with stable chronic obstructive lung disease were studied. Their clinical and physiological details are summarised in table 1 . Their mean age was 69.2 (SD 3.8) years (range 63-75). Three patients had clinical and physiological evidence of emphysema with a carbon monoxide transfer factor (TLCO) corrected for alveolar volume (KCO) of less than $80 \%$ of predicted values, and two had a body weight less than $90 \%$ of predicted values. All had spirometric evidence of severe airflow obstruction with a mean forced 
Table 1 Baseline clinical and physiological details of patients

\begin{tabular}{|c|c|c|c|c|c|c|c|c|c|c|c|c|c|}
\hline \multirow[b]{2}{*}{$\begin{array}{l}\text { Case } \\
\text { No }\end{array}$} & \multirow[b]{2}{*}{$\begin{array}{l}\begin{array}{l}\text { Age } \\
\text { (years) }\end{array} \\
\end{array}$} & \multirow[b]{2}{*}{ Sex } & \multicolumn{2}{|c|}{ Weight } & \multirow[b]{2}{*}{ Diagnosis } & \multicolumn{2}{|c|}{$F E V_{1}$} & \multicolumn{2}{|c|}{$T L C$} & \multicolumn{2}{|l|}{ Kco } & \multirow[b]{2}{*}{$\begin{array}{l}\mathrm{PaO}_{2} \\
(\mathrm{kPa})\end{array}$} & \multirow[b]{2}{*}{$\begin{array}{l}\mathrm{PaCO}_{2} \\
(\mathrm{kPa})\end{array}$} \\
\hline & & & kg & $\begin{array}{l}\% \\
\text { pred }\end{array}$ & & $l$ & $\begin{array}{l}\% \\
\text { pred }\end{array}$ & $l$ & $\begin{array}{l}\% \\
\text { pred }\end{array}$ & * & $\begin{array}{l}\% \\
\text { pred }\end{array}$ & & \\
\hline $\begin{array}{r}1 \\
2 \\
3 \\
4 \\
5 \\
6 \\
7 \\
8 \\
9 \\
10\end{array}$ & $\begin{array}{l}64 \\
73 \\
69 \\
70 \\
72 \\
68 \\
63 \\
71 \\
75 \\
67\end{array}$ & $\begin{array}{l}M \\
M \\
M \\
M \\
F \\
M \\
M \\
F \\
F \\
M\end{array}$ & $\begin{array}{l}52 \cdot 5 \\
69 \cdot 5 \\
59 \cdot 5 \\
80 \cdot 3 \\
65 \cdot 3 \\
58 \cdot 7 \\
71 \cdot 2 \\
64 \cdot 8 \\
54 \cdot 4 \\
60 \cdot 5\end{array}$ & $\begin{array}{r}85 \cdot 6 \\
94 \cdot 2 \\
90 \cdot 3 \\
117 \cdot 2 \\
97 \cdot 7 \\
95 \cdot 3 \\
105 \cdot 8 \\
99 \cdot 1 \\
88 \cdot 0 \\
107 \cdot 9\end{array}$ & $\begin{array}{l}\text { COLD, emphysema } \\
\text { COLD, cor pulmonale } \\
\text { COLD, emphysema } \\
\text { COLD, cor pulmonale } \\
\text { COLD, cor pulmonale } \\
\text { COLD } \\
\text { COLD, cor pulmonale } \\
\text { COLD } \\
\text { COLD, emphysema } \\
\text { COLD, cor pulmonale }\end{array}$ & $\begin{array}{l}0 \cdot 42 \\
0 \cdot 50 \\
0 \cdot 74 \\
0 \cdot 64 \\
0 \cdot 73 \\
0 \cdot 80 \\
1 \cdot 08 \\
0 \cdot 50 \\
0 \cdot 54 \\
0 \cdot 67\end{array}$ & $\begin{array}{l}16 \cdot 9 \\
23 \cdot 1 \\
34 \cdot 3 \\
22 \cdot 7 \\
48 \cdot 6 \\
37 \cdot 0 \\
45 \cdot 2 \\
26 \cdot 4 \\
33 \cdot 6 \\
25 \cdot 8\end{array}$ & $\begin{array}{l}5 \cdot 8 \\
6 \cdot 1 \\
8 \cdot 7 \\
6 \cdot 0 \\
5 \cdot 6 \\
6 \cdot 7 \\
6 \cdot 7 \\
6 \cdot 6 \\
5 \cdot 9 \\
4 \cdot 4\end{array}$ & $\begin{array}{l}112 \\
110 \\
146 \\
109 \\
103 \\
121 \\
112 \\
155 \\
132 \\
104\end{array}$ & $\begin{array}{l}0 \cdot 78 \\
3 \cdot 26 \\
2 \cdot 39 \\
2 \cdot 47 \\
1 \cdot 96 \\
1 \cdot 63 \\
3 \cdot 23 \\
2 \cdot 15 \\
2 \cdot 01 \\
3 \cdot 32\end{array}$ & $\begin{array}{l}38 \cdot 5 \\
93 \cdot 1 \\
78 \cdot 6 \\
82 \cdot 3 \\
68 \cdot 7 \\
49 \cdot 3 \\
84 \cdot 7 \\
81 \cdot 9 \\
43 \cdot 0 \\
95 \cdot 2\end{array}$ & $\begin{array}{l}7 \cdot 85 \\
9 \cdot 06 \\
7 \cdot 87 \\
7 \cdot 06 \\
7 \cdot 60 \\
8 \cdot 13 \\
7 \cdot 35 \\
7 \cdot 37 \\
7 \cdot 62 \\
7 \cdot 86\end{array}$ & $\begin{array}{l}5 \cdot 89 \\
5 \cdot 27 \\
4 \cdot 87 \\
7 \cdot 26 \\
7 \cdot 18 \\
5 \cdot 49 \\
6 \cdot 50 \\
6 \cdot 35 \\
5 \cdot 05 \\
6 \cdot 70\end{array}$ \\
\hline $\begin{array}{l}\text { Mean } \\
\text { SD }\end{array}$ & $\begin{array}{r}69 \cdot 2 \\
\cdot 3 \cdot 8\end{array}$ & & $\begin{array}{r}63 \cdot 7 \\
8 \cdot 4\end{array}$ & $\begin{array}{r}98 \cdot 1 \\
9 \cdot 8\end{array}$ & & $\begin{array}{l}0.66 \\
0.19\end{array}$ & $\begin{array}{l}31 \cdot 4 \\
10 \cdot 2\end{array}$ & $\begin{array}{l}6 \cdot 2 \\
1 \cdot 1\end{array}$ & $\begin{array}{r}120 \\
18\end{array}$ & $\begin{array}{l}2.33 \\
0.81\end{array}$ & $\begin{array}{l}71.5 \\
20.8\end{array}$ & $\begin{array}{l}7 \cdot 78 \\
0.57\end{array}$ & $\begin{array}{l}6 \cdot 06 \\
0 \cdot 88\end{array}$ \\
\hline
\end{tabular}

$\mathrm{FEV}_{1}=$ forced expiratory volume in one second; TLC = total lung capacity; $\mathrm{KcO}=$ carbon monoxide transfer factor; $\mathrm{PaO}_{2}=$ arterial oxygen tension; $\mathrm{PaCO}_{2}=$ arterial carbon dioxide tension; COLD $=$ chronic obstructive lung disease; $\%$ pred $=$ percentage of predicted values.

${ }^{\star} \mathrm{mmol} / \mathrm{min} / \mathrm{kPa} / \mathrm{l}$

expiratory volume in one second $\left(\mathrm{FEV}_{1}\right)$ of 0.66 $(0.19) 1(31.4 \%(10.2 \%)$ predicted); none showed a $20 \%$ or greater improvement in $\mathrm{FEV}_{1}$ after nebulised salbutamol. The patients were hypoxaemic when breathing room air, with a mean $\mathrm{PaO}_{2}$ of $7.8(0.57) \mathrm{kPa}$. The mean $\mathrm{PaCO}_{2}$ was $6.1(0.88) \mathrm{kPa}$, with five patients being hypercapnic-that is, $\mathrm{PaCO}_{2}$ greater than 6.0 $\mathrm{kPa}$. Five patients had clinical evidence of cor pulmonale, four of them being hypercapnic.

Patients were studied when their condition was clinically stable without evidence of infection. All patients had been in remission and out of hospital for between one and eight months. All were taking inhaled or nebulised salbutamol, or both, eight nebulised ipratropium bromide, five an inhaled corticosteroid, five a loop diuretic, four long term oxygen therapy, and four an oral theophylline. None of the patients was taking oral corticosteroids, hypnotics, or other centrally acting drugs. The patients' treatment was not adjusted during the study period. All patients were asked to take their treatments at the same time each morning before each study - that is, two hours before.

All patients gave full informed consent and the study was approved by the Central Oxford Research Ethics Committee.

\section{STUDY PROTOCOL}

Patients were tested after an overnight fast on three study days, three days apart, in a double blind randomised crossover fashion. On each day they took either a carbohydrate rich drink (Ensure-plus, Abbot Laboratories), a fat rich drink (Pulmocare, Abbot Laboratories), or an equal volume $(613 \mathrm{ml})$ of a non-calorific control drink (artificially sweetened water). The calorific drinks provided $920 \mathrm{kcal}$ of energy and were ingested steadily over 10 minutes. The constituent energy profiles for the calorific drinks were carbohydrate $53 \%$, fat $32 \%$, and protein 15\% for Ensure-plus and carbohydrate $28 \%$, fat $55 \%$, and protein $17 \%$ for Pulmocare. The constituent energy profile of Ensure-plus was very similar to that of the normal diet of our patients with chronic obstructive lung disease as assessed by a seven day dietary record kept in the week preceding the first study, when the mean dietary intake of carbohydrate was $58 \%$ (range $50-65 \%$ ), of fat $30 \%$ (range $25-40 \%$ ), and of protein $12 \%$ (range $6-15 \%$ ).
Thirty minutes before and 30 minutes after the ingestion of each liquid meal expired gas was sampled for the measurement of minute ventilation $(\dot{\mathrm{V}}), \dot{\mathrm{V}} \mathrm{CO}_{2}, \dot{\mathrm{V}} \mathrm{O}_{2}$, and $\mathrm{RQ}$. At these times arterial blood was also drawn for estimation of gas tensions; $\mathrm{FEV}_{1}$ and forced vital capacity (FVC) were measured with a wedge bellows spirometer.

Gas exchange was measured while the subject was sitting, wearing a nose clip, and breathing through a mouthpiece connected to a low resistance two way valve. Expired gas from a six litre glass mixing chamber was analysed continually after patients had adjusted to the mouthpiece and baseline values had been stable for 10 minutes (variability in baseline measurements less than $4 \%$ ). Minute ventilation and expired gas concentrations were determined every minute for five minutes and from these the mean $\dot{\mathrm{V}}, \dot{\mathrm{V}} \mathrm{O}_{2}, \dot{\mathrm{V}} \mathrm{CO}_{2}$, and $\mathrm{RQ}$ were calculated. A dry gasometer (Parkinson Cowan) fitted with an electrical output and recorded on a Gould Brush 260 recorder was used to measure VE. Expired gas oxygen concentration was measured with a paramagnetic analyser (Taylor Servomex Type OA 272). Expired gas carbon dioxide concentration was measured with an infrared analyser (Beckman LB2). The analysers were calibrated with known gas mixtures, the oxygen analyser with air $(20.93 \%$ oxygen) and a $15 \%$ oxygen mixture, and the carbon dioxide analyser with air and a 5\% carbon dioxide mixture. All gas volumes were converted to standard temperature, pressure, and saturation conditions. The following indices were then calculated:

$$
\mathrm{RQ}=\mathrm{FECO}_{2} / \mathrm{FIO}_{2} \times \frac{\mathrm{FEN}_{2}}{\mathrm{FIN}_{2}}-\mathrm{FEO}_{2}
$$

where $\mathrm{FEO}_{2}$ and $\mathrm{FECO}$, were respectively the fractional concentrations of oxygen and carbon dioxide in expired gas and $\mathrm{FIN}_{2}$ and $\mathrm{FEN}_{2}$ were respectively the fractional concentrations of nitrogen in inspired and expired gas.

$$
\begin{aligned}
& \dot{\mathrm{V}} \mathrm{CO}_{2}=\dot{\mathrm{VE}} \times \mathrm{FECO}_{2} \\
& \dot{\mathrm{VO}_{2}}=\dot{\mathrm{V}} \mathrm{CO}_{2} / \mathrm{RQ}
\end{aligned}
$$

Samples for arterial blood gas tensions were taken while the patient was seated comfortably breathing room air and analysed within five minutes with a Radiometer ABL2 acid base analyser. 
Forty minutes before and 45 minutes after each liquid meal patients walked for six minutes along a flat indoor corridor. On a preliminary day all patients performed three practice walks to ensure their baseline measurements were stable. Before and at the end of each six minute walk patients were asked to rate their "sense of effort to breathe" with a Borg category scale. ${ }^{10}$ The scale consisted of 15 numbers from 6 to 20 listed vertically down the left hand side of a page and next to every odd number were descriptions categorising the perceived magnitude of the sensation, ranging from "very, very light" to "very, very hard."

In the first patient studied measurements of gas exchange and six minute walking distance were repeated at one, two, and three hours after each calorific drink to determine the time course of recovery of any changes that developed. In addition, on the day of taking the non-calorific drink, the same patient had these measurements made one and two hours after his normal drug treatment, immediately before the drink, to assess any possible drug effects.

The significance of the changes after each drink was determined by analysis of variance and paired $t$ test. Correlations between changes in $\dot{V} E, \dot{V} \mathrm{CO}_{2}, \dot{\mathrm{V}} \mathrm{O}_{2}, \mathrm{RQ}$, arterial blood gas tensions, and six minute walking distance were measured by linear regression analysis.

\section{Results \\ Lung function measurements on entry to the study are summarised in table 1 . The mean changes in FEV 1 and FVC after each of the calorific drinks are shown in table 2. There were small and insignificant reductions in both varia- bles, with no significant differences between the two drinks.}

ADVERSE EFFECTS AND TASTE OF TEST DRINKS All drinks were given in unmarked containers and both the patients and investigators were blind to their contents. No serious adverse effects of the drinks were noted during the course of the study. Four patients reported nausea or bloating after Ensure-plus and three reported nausea or bloating and one mild diarrhoea after Pulmocare. All side effects were mild and transient. No adverse effects were reported after the non-calorific drink. Patients generally liked the taste of the drinks, although two patients described the Ensure-plus as being too sweet and sickly. Half the patients thought Ensure-plus was creamier than Pulmore and half thought the reverse.

EFFECT OF TEST DRINKS ON GAS EXCHANGE, BLOOD GASES, AND LUNG FUNCTION

Half the patients received Ensure-plus first and half Pulmocare first. There were no detectable crossover effects.

The results of the effects of the calorific drinks on respiratory gas exchange, arterial blood gas tensions, lung function, and six minute walking distance are summarised in table 2.

$\mathrm{VCO}_{2}$ increased by $25 \cdot 7 \%(5 \cdot 4 \%)$ after Ensure-plus and by $17 \cdot 7 \%(4 \cdot 1 \%)$ after Pulmocare; the difference between the two was highly significant $(\mathrm{p}<0.001) . \dot{\mathrm{V}} \mathrm{o}_{2}, \dot{\mathrm{V}}_{\mathrm{E}}$, and $\mathrm{RQ}$ also increased after each drink and the increase in all these was significantly greater after Ensure-plus than Pulmocare. $\mathrm{PaO}_{2}$ increased by a small amount after both drinks - that is, by $3.9 \%(2.7 \%)$ after Ensure-plus and by $2.4 \%$ $(1.7 \%)$ after Pulmocare-but the difference between the two was not significant. $\mathrm{PaCO}_{2}$ increased by $1.3 \%(1.1 \%)$ after Ensure-plus and by $0.1 \%(0.5 \%)$ after Pulmocare; this difference was significant $(p<0.02)$.

\section{EFFECT OF TEST DRINKS ON WALKING DISTANCE} AND BORG SCORES

The mean six minute walking distance decreased significantly after Ensure-plus (by $8.2 \%(3 \cdot 7 \%)$ ) but not after Pulmocare (by $1.2 \%(2 \cdot 5 \%))$; the difference between these two was highly significant ( $\mathrm{p}<0.001$ ).

The decrease in six minute walking distance after Ensure-plus was significantly correlated with the increase in $\operatorname{VCO}_{2}(r=0.56, p<0.02)$, whereas there was no significant correlation between the two variables after Pulmocare (fig 1). The six minute walk before the test drinks resulted in similar increases in Borg scores on all three test days (table 3 ). There were no significant changes in resting Borg scores after the test drinks. The six minute walk after Ensure-plus resulted in a greater increase in Borg score $(6.1(0.9))$ than that obtained after Pulmocare $(4.9(0.8))$ or the control drink $(4.8(0.6))$. The increase in Borg score following the six minute walk after Ensure-plus was significantly correlated with the increase in $\dot{V}_{E}$ $(\mathrm{r}=0.51, \mathrm{p}<0.05)$ and the increase in $\mathrm{VCO}_{2}(\mathrm{r}$

Table 2 Mean (SD) values before and after each test drink in 10 patients with chronic obstructive lung disease

\begin{tabular}{|c|c|c|c|c|c|c|c|c|c|c|c|c|c|c|c|c|}
\hline & \multicolumn{5}{|c|}{ Non-calorific drink } & \multicolumn{5}{|c|}{ Ensure-plus } & \multicolumn{5}{|c|}{ Pulmocare } & \multirow[b]{2}{*}{$p^{\star}$} \\
\hline & Before & & After & & $\begin{array}{l}\% \\
\text { Change }\end{array}$ & Before & & After & & $\begin{array}{l}\% \\
\text { Change } \\
\end{array}$ & Before & & After & & $\begin{array}{l}\% \\
\text { Change }\end{array}$ & \\
\hline 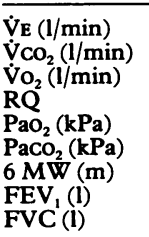 & $\begin{array}{c}9.5 \\
0.24 \\
0.28 \\
0.86 \\
7.68 \\
6.08 \\
228 \\
0.66 \\
1.84\end{array}$ & $\begin{array}{c}(2.0) \\
(0.03) \\
(0.04) \\
(0.04) \\
(0.58) \\
(0.85) \\
(57) \\
(0.19) \\
(0.48)\end{array}$ & $\begin{array}{r}9.4 \\
0.24 \\
0.27 \\
0.87 \\
7.69 \\
6.07 \\
229 \\
0.66 \\
1.85\end{array}$ & $\begin{array}{c}(1.9) \\
(0.03) \\
(0.03) \\
(0.05) \\
(0.57) \\
(0.86) \\
(56) \\
(0.19) \\
(0.47)\end{array}$ & $\begin{array}{r}-1.1 \\
0 \\
-3.6 \\
1.2 \\
0.1 \\
-0.2 \\
0.4 \\
0 \\
0.5\end{array}$ & $\begin{array}{r}9.3 \\
0.24 \\
0.27 \\
0.89 \\
7.66 \\
6.06 \\
227 \\
0.65 \\
1.85\end{array}$ & $\begin{array}{c}(2.1) \\
(0.03) \\
(0.03) \\
(0.06) \\
(0.59) \\
(0.90) \\
(58) \\
(0.21) \\
(0.50)\end{array}$ & $\begin{array}{c}11.1 \\
0.30 \\
0.29 \\
1.02 \\
7.95 \\
6.13 \\
210 \\
0.64 \\
1.83\end{array}$ & $\begin{array}{c}(2 \cdot 8) \\
(0.05) \\
(0.04) \\
(0.08) \\
(0.60) \\
(0.95) \\
(57) \\
(0.22) \\
(0.50)\end{array}$ & $\begin{array}{r}19.4 \\
25.7 \\
7.4 \\
14 \cdot 4 \\
3.9 \\
1.3 \\
-8.2 \\
-0.2 \\
-1.2\end{array}$ & $\begin{array}{r}9.2 \\
0.23 \\
0.27 \\
0.88 \\
7.69 \\
6.06 \\
225 \\
0.65 \\
1.82\end{array}$ & $\begin{array}{c}(1.9) \\
(0.03) \\
(0.03) \\
(0.05) \\
(0.57) \\
(0.84) \\
(56) \\
(0.18) \\
(0.47)\end{array}$ & $\begin{array}{c}10.5 \\
0.28 \\
0.28 \\
0.92 \\
7.87 \\
6.07 \\
222 \\
0.66 \\
1.81\end{array}$ & $\begin{array}{c}(2.4) \\
(0.04) \\
(0.04) \\
(0.05) \\
(0.58) \\
(0.86) \\
(54) \\
(0.19) \\
(0.47)\end{array}$ & $\begin{array}{r}14.1 \\
17.7 \\
3.7 \\
4.5 \\
2.4 \\
0.1 \\
-1.2 \\
-0.2 \\
-0.3\end{array}$ & $\begin{array}{l}<0.02 \\
<0.001 \\
<0.05 \\
<0.01 \\
\text { NS } \\
<0.02 \\
<0.001 \\
\text { NS } \\
\text { NS }\end{array}$ \\
\hline
\end{tabular}

^For the significance of differences between the changes in the measured variables between Ensure-plus and Pulmocare.

$\dot{\mathrm{V}}=$ minute ventilation; $\dot{\mathrm{V}} \mathrm{CO}_{2}=$ carbon dioxide production; $\dot{\mathrm{V}} \mathrm{O}_{2}=$ oxygen consumption; $\mathrm{RQ}=$ respiratory quotient; $\mathrm{PaO} \mathrm{O}_{2}=$ arterial oxygen tension; $\mathrm{PaCO}_{2}=$ arterial carbon dioxide tension; $6 \mathrm{MW}=$ six minute walking distance; $\mathrm{FEV} \mathrm{EV}_{1}=$ forced expiratory volume in one second; $\mathrm{FVC}=$ forced vital capacity. 


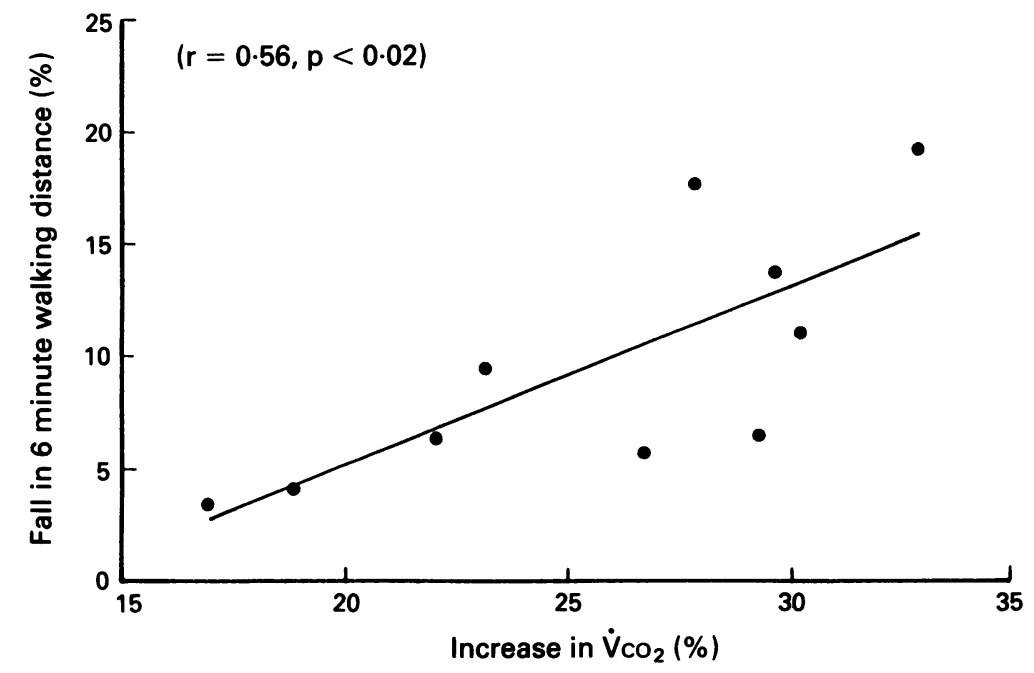

Relation between increase in carbon dioxide production $\left(\dot{V} \mathrm{CO}_{2}\right)$ and fall in six minute walking distance after the carbohydrate rich drink Ensure-plus in 10 patients with chronic obstructive lung disease.
Compared with the non-calorific control drink, Pulmocare resulted in significant increases in $\dot{\mathrm{V}}_{\mathrm{E}}(\mathrm{p}<0.002), \dot{\mathrm{V}}_{2}(\mathrm{p}<0.001)$, $\mathrm{Vo}_{2}(\mathrm{p}<0.005)$, and $\mathrm{RQ}(\mathrm{p}<0.05)$, whereas the changes in $\mathrm{PaO}_{2}, \mathrm{PaCO}_{2}$, six minute walking distance, Borg scores, $\mathrm{FEV}_{1}$, and FVC were similar.

\section{Discussion}

This study shows that carbohydrate rich loads may increase $\dot{\mathrm{VCO}}_{2}, \dot{\mathrm{Vo}}_{2}, \mathrm{RQ}$, and $\mathrm{PaCO}_{2}$ and decrease exercise tolerance to a greater extent than fat rich loads of identical calorific value in patients with chronic obstructive lung disease. Gas exchange was measured 30 minutes after finishing the test drinks because (a) our preliminary studies showed that the peak $\dot{\mathrm{VCO}}_{2}$ occurred around this time; $(b)$ previous similar studies in normal subjects ${ }^{6}$ and patients with chronic obstructive lung disease ${ }^{411}$ used this protocol; (c) a previous study in cats showed that peak postprandial $\mathrm{PaCO}_{2}$ occurred at this time $^{12}$; and $(d)$ the peak RQ after an oral sugar load also occurs around 30 minutes postprandially. ${ }^{1314}$

The perceived effort to breathe (the Borg score) following a six minute walk also increased more after the carbohydrate rich than the fat rich load. The decrease in exercise tolerance and increase in Borg score both correlated with the increase in $\mathrm{VCO}_{2}$ after the carbohydrate rich load. In the patient who was studied for several hours after the carbohydrate rich load the changes in $\dot{\mathrm{VCO}}_{2}$ and six minute walking distance persisted for at least two hours. Although the changes seen after the calorific drinks were generally small, in a few patients they were substantial and may have important clinical implications for the diet and timing of meals in such patients.

In the past decade several studies have showed that large carbohydrate loads in patients being ventilated, even without respiratory disease, can result in an increase in $\mathrm{VCO}_{2}$ and precipitate respiratory distress ${ }^{715}$ and rarely respiratory failure. ${ }^{3}$ In patients with respiratory disease carbohydrate loads may not only increase $\mathrm{VCO}_{2}$ but also $\mathrm{PaCO}_{2}$ and in such patients may therefore be more likely to lead to the development or worsening of respiratory failure. ${ }^{3516}$ Normal subjects given a carbohydrate load increase their $\dot{\mathrm{V}} \mathrm{CO}_{2}, \dot{\mathrm{V}} \mathrm{O}_{2}$, and $\mathrm{RQ}$ to a similar extent ${ }^{6}$ but unlike patients with chronic obstructive lung disease do not increase their $\mathrm{PaCO}_{2}$, presumably because they are able to increase their ventilation accordingly. In patients with stable chronic obstructive lung disease a pure carbohydrate load is

Table 3 Mean (range) Borg scores before and after each test drink

\begin{tabular}{|c|c|c|c|c|c|c|}
\hline & \multicolumn{3}{|l|}{ Before drink } & \multicolumn{3}{|l|}{ After drink } \\
\hline & Before $6 \mathrm{MW}$ & After $6 M W$ & Change & Before $6 \mathrm{MW}$ & After $6 \mathrm{MW}$ & Change \\
\hline $\begin{array}{l}\text { Non-calorific drink } \\
\text { Ensure-plus } \\
\text { Pulmocare }\end{array}$ & $\begin{array}{l}11 \cdot 2(9-12) \\
11 \cdot 2(9-13) \\
11 \cdot 4(19-13)\end{array}$ & $\begin{array}{l}16 \cdot 0(14-18) \\
16 \cdot 1(14-19) \\
16 \cdot 2(14-18)\end{array}$ & $\begin{array}{l}4 \cdot 8 \\
4 \cdot 9 \\
4 \cdot 8\end{array}$ & $\begin{array}{l}11 \cdot 1(9-12) \\
11 \cdot 5(10-14) \\
11 \cdot 6(9-13)\end{array}$ & $\begin{array}{l}15.9(14-17) \\
17 \cdot 6(15-20) \\
16.5(15-19)\end{array}$ & $\begin{array}{l}4 \cdot 8 \\
6 \cdot 1 \star \\
4 \cdot 9\end{array}$ \\
\hline
\end{tabular}


known to increase $\mathrm{VCO}_{2}{ }^{4511}$ and decrease exercise tolerance, as assessed by a 12 minute walk. ${ }^{4}$ In our patients a carbohydrate rich meal (53\% carbohydrate) resulted in a greater increase in $\mathrm{VCO}_{2}$ and a greater fall in exercise tolerance as determined by a six minute walk than did a fat rich meal ( $28 \%$ carbohydrate). The fall in exercise tolerance after the carbohydrate rich meal correlated with the increase in $\mathrm{VCO}_{2}$, suggesting an important association between the change in gas exchange and change in functional capacity.

Maximal exercise capacity, as measured by incremental cycle ergometry, decreases after a pure carbohydrate load ${ }^{17}$ and after a carbohydrate rich load of identical calorific value. ${ }^{18}$ The results of our study show that forms of exercise other than the maximal stress imposed by cycle ergometry may also be impaired and that such submaximal exercise may be more relevant to the abilities and normal exercise tolerance of severely limited patients. Moreover, the reduction in exercise tolerance was significantly worse after the carbohydrate rich than the fat rich load. This suggests that even relatively small changes in the constitution of meals, in terms of carbohydrate and fat, may have significant effects on exercise tolerance and breathlessness in patients with severe chronic obstructive lung disease.

There are several possible mechanisms by which a carbohydrate load may decrease exercise performance. Changes in the proportion of fat and carbohydrate metabolised will alter respiratory gas exchange and ventilation, with carbohydrate loads causing an increase in both $\dot{\mathrm{V}} \mathrm{CO}_{2}$ and $R Q .{ }^{681314}$ We suggest that the decrease in walking distance in our patients occurred because ventilation at any given walking pace increased more, with a greater rise in $\dot{\mathrm{V}} \mathrm{CO}_{2}$, after the carbohydrate rich meal than the fat rich meal. Although ventilation during the six minute walk was not measured in our study, consistently greater increases in resting ventilation occurred immediately before the six minute walk after the carbohydrate rich meal. Significant increases in $\dot{V}_{E}$ have been reported during cycle ergometry after a pure carbohydrate meal. ${ }^{17}$

The Borg score of the perceived effort to breathe increased significantly more at the end of the six minute walk after the carbohydrate rich meal than after the fat rich meal. In addition, the increase in Borg score was significantly correlated with the increase in both resting $\mathrm{VE}$ and $\dot{\mathrm{VCO}}_{2}$ after the carbohydrate rich but not the fat rich meal. The Borg score correlates well with minute ventilation during exercise, both in patients with chronic obstructive lung disease $\mathrm{e}^{18}{ }^{19}$ and in normal subjects ${ }^{20}$ and our findings are consistent with this. Although the changes in exercise tolerance and breathlessness in our patients were generally small (maximum fall in six minute walking distance $15 \%$, maximum increase in Borg score $14 \%$ ), the combination of feeling more breathless and attaining a lower level of exercise may in some patients be of substantial clinical importance.

Various drugs used in the treatment of patients with chronic obstructive lung disease, including $\beta_{2}$ agonists and methylxanthines, can increase $\dot{\mathrm{VCO}}_{2}$ and $\dot{\mathrm{VO}}_{2}$, ${ }^{21}$ but there was only a small and insignificant increase in these measurements in our patient two hours after taking his normal treatment. Such small changes are unlikely to have contributed to the substantial changes seen after the calorific drinks. All drug treatments were taken at the same time before each study, further reducing the risk of any drug effect.

Several studies have emphasised the frequency of malnutrition in patients with chronic obstructive lung disease, ${ }^{223}$ as well as its adverse effects on the respiratory system. ${ }^{24} 25$ As a result, there has been much interest in trying to replete malnourished patients with the disease. ${ }^{26} 27$ Our results show that vigorous attempts to treat malnutrition in patients with chronic obstructive lung disease, particularly with large carbohydrate rich meals, may produce adverse effects on respiratory gas exchange, exercise tolerance, and breathlessness, and we suggest that such factors should be carefully monitored in these patients. Physicians attempting nutritional support in patients with chronic obstructive lung disease should be aware that even comparatively small changes in the constitution of their meals, in terms of both total calories and the proportions of carbohydrate and fat, may have important effects. Further work should attempt to establish the optimal and safest feeding regimens for patients with and without carbon dioxide retention in both stable and acute conditions.

1 Cherniak RM, Snidal DP. The effect of obstruction to breathing on the ventilatory response to $\mathrm{CO}_{2}$.J Clin Invest 1956;35:1286-90.

2 Gribbin HR, Gardinier IT, Heinz GJ, Gibson GJ, Pride NB. Role of impaired inspiratory muscle function in limiting the ventilatory response to carbon dioxide in limiting the ventilatory response to carbon dioxide
chronic airflow obstruction. Clin Sci 1983;64:487-95.

3 Covelli HD, Black JW, Olsen MS, Beckman JF. Respiratory failure precipitated by high carbohydrate loads. Ann Intern Med 1981;95:579-85.

4 Brown SE, Nagenclern RC, McHugh JW, Stansbury DW, Fischerm CE, Light RW. Effects of a large carbohydrate load on walking performance in chronic airflow obstruction. Am Rev Respir Dis 1985;132:960-2.

5 Angelillo VA, Sukhadarshan B, Durfree D, Dahl J, Patterson AJ, O'Donohue WJ. Effects of low and high carbohydrate feeding in ambulatory patients with chronic obstructive pulmonary disease and chronic hypercapnia. Ann Intern Med 1985;103:883-5.

6 Saltzman AA, Salzano JV. Effects of carbohydrate metabolism on respiratory exchange in normal men.J Appl Physiol 1971;30:228-31.

7 Askanazi J, Rosenbaum SH, Hyman AI, Silverberg PA, Milic-Emili J, Kinney JM. Respiratory changes induced by large glucose loads of total parental nutrition. JAMA 1980;243:1444-7.

8 Rodriguez JL, Askanazi J, Weissman C, Hensle TW, Rosenbaum SH, Kinney JM. Ventilatory and metabolic effects of glucose infusions. Chest 1983;88:512-7.

9 Molnar JA, Burke JF. Metabolic and nutritional management. Avoiding the pitfalls. Drugs and Therapeutics 1984; 38:44-55.

10 Borg G. Perceived exertion as an indicator of somatic stress. Scand J Rehabil Med 1970;2:92-8.

11 Gieseke T, Gurushanthaiah G, Glauser FL. Effects of carbohydrate on carbon dioxide excretion in patients with airways disease. Chest 1977;71:55-8.

12 On LC, Tenney SM. Post-prandial rise in alveolar $\mathrm{CO}_{2}$ and ventilatory response in cats. Respir Physiol 1974;22:263-7.

13 Bachman G, Haldi J. A comparative study of the respiratory quotient following the ingestion of oral glucose and of quotient following the ingestion of oral glucose and of
fructose as affected by the lactate acid and carbon dioxide fructose as affected by the lactate acid and carbor
changes in the blood. $J$ Nutr 1937;13:157-78.

14 Edwards HT, Bensley EH, Hill DB, Carpenter TM. Human respiratory quotients in relation to alveolar carbon dioxide respiratory quotients in relation to alveolar carbon dioxide and blood lactic acid after infestion of

15 Askanazi J, Elwyn DH, Silverberg BS, Rosenbaum SH, Kinney JM. Respiratory distress secondary to a high carbohydrate load. A case report. Surgery 1980;87:596-9. 
16 Dark DS, Pingleton SK, Kerby GR. Hypercapnia during weaning. A complication of nutritional support. Chest 1985;88:141-3.

17 Brown SE, Weiner S, Brown SA, Marcelli PA, Light RW. Exercise performance following a carbohydrate rich load in chronic aifflow obstruction $J$ Appl Physiol 1985; 58:1340-6.

18 Stark RD, Gambles SA, Chatterjee SS. An exercise test to assess clinical dyspnoea: estimation of reproducibility and sensitivity. $B r J$ Dis Chest 1982;76:269-78.

19 Silverman M, Barry J, Hellerstein H, Janos J, Kelsen S. Variability of the perceived sense of effort in breathing during exercise in patients with chronic obstructive pulmonary disease. Am Rev Respir Dis 1988;137:206-9.

20 Adams L, Chronos N, Lane R, Guz A. The measurement of breathlessness in normal subjects; validity of two scaling techniques. Clin Sci 1985;69:7-16.

21 Javaheri S, Guerra L. Lung function, hypoxic and hypercapnic ventilatory responses and respiratory muscle strength in normal subjects taking oral theophylline. Thorax 1990;45:743-7.
22 Hunter AMB, Carey MA, Larsh HW. The nutritional status of patients with chronic obstructive pulmonary disease. Am Rev Respir Dis 1981;124:376-81.

23 Openbrier DR, Irwin MM, Rogers RM, Gotlieb GB, Dauber JH, Van Thiel DH. Nutritional status and lung Dauber $\mathrm{JH}$, Van Thiel DH. Nutritional status and lung function in patients with emphy

24 Boushy SF, Adhikari PK, Sakamoto A, Lewis BM. Factors affecting prognosis in emphysema. Dis Chest 1964;45: 402-11.

25 Arora NS, Rochester DF. Respiratory muscle strength and maximal voluntary ventilation in undernourished patients. Am Rev Respir Dis 1982;126:5-8.

26 Wilson DO, Rogers DM, Saunders MH, Pennock BE, Reilly JJ. Nutritional intervention in malnourished patients with emphysema. Am Rev Respir Dis 1986;134:672-7.

27 Efthimiou J, Fleming J, Gomes S, Spiro SG. The effect of supplementary oral nutrition in poorly nourished patients supplementary oral nutrition in poorly nourished patients
with chronic obstructive pulmonary disease. Am Rev with chronic obstructive pulm
Respir Dis 1988;137:1075-82. 